\title{
Higher Energy Does Not Mean Better Outcome Following Endovenous Laser Ablation of Great Saphenous Vein
}

\author{
Celalettin Karatepe' ${ }^{1}$ Mustafa Aldemir², Bayer Çınar³ ${ }^{3}$ Akif Önalan4, Halim Issever5, \\ Onur S. Goksel ${ }^{4}$ \\ ${ }^{1}$ Cardiovascular Surgery Department, Medical Faculty, Mustafa Kemal University, Antakya, Turkey \\ ${ }^{2}$ Cardiovascular Surgery Department, School of Medicine, Afyon Kocatepe University, Afyonkarahisar, Turkey \\ ${ }^{3}$ Cardiovascular Surgery Department, Medical Park Hospital, Istanbul, Turkey \\ ${ }^{4}$ Cardiovascular Surgery Department, Istanbul Medical Faculty, Istanbul University, Istanbul, Turkey \\ ${ }^{5}$ Biostatistics and Public Health Department, Istanbul Medical Faculty, Istanbul University, Istanbul, Turkey \\ Email: drcelalettin@hotmail.com
}

Received 3 September 2014; revised 9 October 2014; accepted 31 October 2014

Copyright (C) 2014 by authors and Scientific Research Publishing Inc.

This work is licensed under the Creative Commons Attribution International License (CC BY).

http://creativecommons.org/licenses/by/4.0/

(c) (i) Open Access

\begin{abstract}
Background: Endovenous laser ablation is a relatively newer alternative to treat great saphenous vein insufficiency. We evaluated the efficiency and safety of treatment endovenous laser procedures on the different saphenous vein diameters with different energy levels. Methods: Data regarding endovenous laser ablation of symptomatic chronic great saphenous venous insufficiency in 209 patients were prospectively recorded. Patients were grouped into two main groups based on their diameters as 5 to 7 millimeters (Group A) or more than 7 millimeters (Group B). Patients in each group was randomized into two groups as $>90 \mathrm{~J} / \mathrm{cm}(\mathrm{A1}$ and $\mathrm{B1})$ or $80-90 \mathrm{~J} / \mathrm{cm}(\mathrm{A} 2$ and B2). Postoperative outcome and complications were recorded during follow-ups at 1st week; 1st, 3rd and 6th months to examine the venous reflux and recanalization. Results: Perioperative complaints as pain, cramps and ankle swelling were more commonly observed in $\mathrm{A} 1$ group. Fatigue was more common in A2 and B2 groups. No major complications as deep vein thrombosis or skin burns were observed. Conclusions: Endovenous laser ablation is a safe and effective procedure with a high satisfaction rate shortening hospitalization durations and early ambulant activity. Pain, ankle swelling and fatigue are the most common minor complaints in the early postoperative period.
\end{abstract}

\section{Keywords}

Endovenous Laser Ablation, Great Saphenous Vein, Varices 


\section{Introduction}

Varicose veins (VV) and chronic venous insufficiency are important social and health problems in particularly developed countries occurring in $25 \%$ - 50\% of women and in $7 \%-40 \%$ of men and their prevalence increases with age [1]-[4]. As ageing population with consequently chronic clinical situations has emerged in the industrial world with a longer life-expectancy, Eurostat 2008 data projected that the population older than 65 years old in the total EU27 countries will rise from 17.1\% in 2008 to 30\% in 2060 and it can be assumed that their prevalence will grow. Risk factors for VVs include family history, increasing age, female gender, pregnancy, obesity, standing occupations, or a history of previous deep venous thrombosis. There is a strong familial tendency for VVs. The signs and symptoms of varicose veins include; large veins that can seem just under the surface of skin, mild swelling of ankles and feet, painful, achy, or "heavy" legs, throbbing or cramping in legs, itchy legs especially on the lower leg and ankle, discolored skin in the area around the varicose veins. VV may lead to phlebitis, bleeding and ulcers leading to a therapeutic process with serious burden on individual patient and the society [5]-[8].

As less invasive and more effective alternative to saphenectomy, endovenous laser ablation (EVLA) has been introduced and rapidly popularized in the last decade, it allows avoidance from complications associated with conventional surgery such as prolonged postoperative pain, saphenous nerve injury, hematomas, paresthesia, thrombophlebitis, wound infection and lymphatic vessels injury and even, though rarely, by femoral vessel injury and venous thromboembolism [9]-[15] in addition to high rates of recurrence reaching 20\% - 50\% [16]-[18].

In this prospective randomized therapy, we compared the outcome following EVLA with different energy levels used based on greater saphenous vein diameter.

\section{Patients and Methods}

Following approval by the local ethical committee, 209 symptomatic patients with great saphenous vein (GSV) varicosity and primary saphenofemoral junction (SFJ) insufficiency were enrolled in the study. All patients who were included in this study, had signed the informed consent. The principal examination included a disease history and physical examination in addition to venous duplex ultrasound imaging. Patients were initially allocated into two groups based on their GSV diameter (Group A, diameter of 5 to 7 millimeters; Group B, diameter more than 7 millimeters). Group A consisted of patients randomized into two groups (A1, 47 patients in whom EVLA was performed with $>90 \mathrm{~J} / \mathrm{cm}$; A2, 89 patients in whom EVLA was performed with $80-90 \mathrm{~J} / \mathrm{cm}$ laser). Group B consisted of patients randomized into two groups (B1, 37 patients in whom EVLA was performed with $>90 \mathrm{~J} / \mathrm{cm}$; B2, 36 patients in whom EVLA was performed with $80-90 \mathrm{~J} / \mathrm{cm}$ ). All diameter measurements were made within 1 centimeter of SFJ on duplex examination.

Venous duplex ultrasonography examination of the venous anatomy was performed for each patient before and after the EVLA procedure. The course of GSV, branch varicosities, and perforating veins were identified by inspection and duplex ultrasound. No patients had any signs of deep venous occlusion. The success of the ablation procedure was defined as lack of compressibility of the treated GSV segment, absence of blood flow inside the vein, decreased vein diameter, the palpation of the fibrotic vein, and no deep vein thrombosis during examination.

$980 \mathrm{~nm}$ diode laser was used with tumescent anesthesia for all the 209 patients as described elsewhere [19] [20]. The GSV was inserted at knee level via a percutaneous needle puncture (19-gauge, Seldinger technique) under ultrasound guidance. A 4-Fr guiding catheter was then passed over the $0.035-\mathrm{J}$ tip guide wire 3 - $4 \mathrm{~cm}$ below the SFJ. Once we confirmed the position of the sheath with duplex ultrasound guidance, a $600 \mu \mathrm{m}$ bare-tipped laser fiber was inserted. The distal tip of the laser fiber was positioned 2 - $3 \mathrm{~cm}$ below the SFJ. Then a tumescent local anesthetic solution, which consists of $20 \mathrm{ml}$ 1\% lidocaine and adrenaline (1:100,000) diluted in $500 \mathrm{ml}$ of cold $\left(4^{\circ} \mathrm{C}\right)$ saline was applied perivenously under ultrasound guidance until the collapse of the GSV and a non-echogenic halo were observed around the main trunk of GSV (20). The laser fiber was slowly withdrawn under ultrasound guidance at a velocity of $1 \mathrm{~mm} / \mathrm{s}$ until it reached a distance of $2.0-2.5 \mathrm{~cm}$ from the puncture site of the GSV at the knee level. Thigh-high, class II graduated compression stockings ( 35 - $40 \mathrm{mmHg}$ ) were applied for 8 weeks in all patients. Mobilization of the patients was promoted in all patients as early as within 2 hours postoperatively.

Any complication as ecchymosis, skin burn, paresthesias, induration, edema, thrombosis, thrombophlebitis, infection or patient complaints (pain, cramp, ankle swelling, fatigue, pruritus) were evaluated and recorded at 1st 
week; 1st, 3rd and 6th months follow-ups with clinical examination and duplex ultrasound to rule out venous reflux and recanalization or deep vein thrombosis. Patient "venous clinical severity score (VCSS)" assessment and records were kept prospectively.

Statistical analysis was performed with SPSS 21.0 (Statistical Package for the Social Sciences, SPSS Inc.). Continuous variables are reported as mean \pm standard deviation (SD). Significance was accepted for a $P$ value of less than 0.05 .

\section{Results}

209 patients (141 females; 67\%) with the mean age of $38.1 \pm 11$ years underwent EVLA. The mean body mass index (BMI) was $27.6 \pm 4.8$. Distribution of female gender was similar among the 4 groups. $38 \%$ of patients had BMI greater than 25 and 23\% had obesity (BMI > 30). A family history of varicose veins was presented in 113 patients (54\%). 36 of patients had mild to moderate deep venous insufficiency.

EVLA procedure was technically successful in all patients with complete ablation of GSV in all patients. No patients experienced any adverse events related to local anesthetic or adrenaline. The procedure was carried out with local tumescent anesthesia in all patients. All patients recovered well in the first postoperative week and all returned to their daily activities within 3 days after the surgery. There were no serious complications related to the EVLA procedure. A thrombus from SFJ into common femoral vein was observed in two patient one of from Group B1 and other one from Group A2 in the postoperative first week. Hematoma in the GSV tunnel was observed in seven patients (3.8\%), with small ecchymosis. One patient from Group B1 had cellulitis on the day 3. One patient from Group B2 had paresthesia on day 5.

Table 1 summarizes the patient characteristics based on GSV diameter. Patients in Group B were significantly older and had higher BMI. Patients with a smaller GSV diameter (Group A) more commonly had a family history of VV $(P<0.05)$. Interestingly, diminishing postoperative complaints in the midterm were more prominent in group B although the mean energy delivered, recanalization rate and the length of GSV were similar. The mean length of ablated venous trunk was $30.6 \pm 2$ centimeters and similar between four groups (A to B) with mean total energy of $2747.7 \pm 2.8$ joules. The differences between the groups did not reach statistical significance. All groups were similar in regard to prior deep vein thrombosis history, family history of varicose veins and postoperative compression stocking protocols. However, prior treatment for varicose veins was more prominent in patients treated with less than $90 \mathrm{~J} / \mathrm{cm}$ regardless of the VSM diameter $(P=0.5)$. Preoperatively, VCSS records in A1, A2, B1 and B2 groups were 2.6, 2.1, 2.5 and 2.1, respectively. At the end of 6th months, VCSSs were $0.29,0.16,0.07$ and 0.05 for the groups. Changes in VCSSs for each group from perioperative period to 6th month controls were significant $(P<0.05)$. However, differences between A1 and A2 as well as B1 and B2 were not significant.

Eight patients had recanalization of GSV within the first six months (4 patients from Group A1, 3 patients from Group B1 and one from Group B2). At 3rd month, 10 patients from Group A1 had disturbing leg pain

Table 1. Summary of the patient characteristics based on greter saphenous vein (GSV) diameter.

\begin{tabular}{|c|c|c|c|}
\hline & Group A (GSV diameter $<7$ mm) & Group B (GSV diameter $>7$ mm) & $\boldsymbol{P}$ \\
\hline Age (years) & $35.5 \pm 4.9$ & $43 \pm 8.5$ & $P<0.05$ \\
\hline Preoperative BMI & $25.7 \pm 5.2$ & $34.6 \pm 3$ & $P<0.05$ \\
\hline Family history (n) & 69 & 45 & $P<0.05$ \\
\hline The mean length of ablated vein (centimeters) & $30 \pm 1.4$ & $32 \pm 2.8$ & NS \\
\hline Total energy delivery (joules) & $2814 \pm 574$ & $2975 \pm 346.5$ & NS \\
\hline Postoperative complaints at 3rd month (n) & 29 & 24 & NS \\
\hline Postoperative complaints at 6th month (n) & 25 & 15 & $P<0.05$ \\
\hline Preoperative VCSS & $3 \pm 1.4$ & 4 & NS \\
\hline Postoperative VCSS at 6th months & $0.3 \pm 0.7$ & $0.6 \pm 0.7$ & NS \\
\hline Recanalization (n) & 4 & 4 & NS \\
\hline
\end{tabular}

BMI: Body mass index; VCSS: Venous clinical severity score. 
compared to 2 patients in A2 $(P<0.05)$ and 3 patients in the former group had ankle swelling $(P<0.01)$. At 6th months, 5 patients from Group A1 had occasional leg cramps when compared to one patient in A2 $(P<0.05)$.

\section{Discussion}

Many studies have shown improvement of the surgical technique of insufficient GSV since the first description of GSV stripping in 1905, but the surgical technique of vein ablation is still not optimal [21] [22]. Many surgeons using a classical tip mounted on the stripper, whereas others favor an invaginated procedure. Hematoma formation is most common in the stripping track after removal of the GSV and can cause severe pain, paresthesias and delayed return to daily activities. As the technical progression and the patients' requirement of safety and aesthetics, the treatment of varicose vein of lower extremities had changed from traditional open surgery to minimal invasive techniques. EVLA has been used widely and effectively due to many advantages as safety, convenience, minimal invasive nature and short convalesce duration. In recent years, it has been reported that the effective rate of the occlusion of GSV ranged from $83.2 \%$ to $93.5 \%$ and $87.2 \%$ to $95.3 \%$ in 1 and 3 years periods, respectively [23]. The tumescent infusion technique is important to ensure that the EVLA procedure is safe and less painful. Perivenous fascial plan containing the tumescent solution provides a safety and prevents thermal injury to adjacent structures. In our observation under ultrasonography assessment during the ablation procedure, the tumescent infusion created a halo around the GSV to compress the vein and to minimize bleeding by mechanical effect and adrenaline's vasoconstrictor action; meanwhile, lidocaine was added to the solution not for anesthetic purposes but for analgesia in the post-operative period, as described by Nisar and colleagues [24].

EVLA is one of the most auspicious of the new techniques such as radiofrequency ablation and chemical ablation, and is becoming an established treatment option for greater and short saphenous vein incompetence. With success rates comparable to those of conventional surgery, EVLA has its own complications such as hematoma, ecchymosis, postoperative pain and paresthesias. The incidence of paresthesia following EVLA is lower ranging $0 \%-7 \%$ of which less than $1 \%$ is permanent [25] [26]. With EVLA the operator can decrease LED in the crural part of GSV either by reducing the power or accelerating the retraction of the fiber. Two main factors contributing to these complications may be perforation and unintentional vein wall contact, which cannot be avoided with any certainty once a bare-tip-fiber was used. In our patient groups; pain, fatigue, paresthesias, itching, cramps, oedema were particularly followed for up to 1 year and at the end of 6th months, all 4 groups showed similar characteristics irrespective of the initial GSV diameter or the energy used. Interestingly, recanalization rates were similar in A and B groups. Similarly, VCSSs were reduced in all groups and difference when compared to preoperative status was similar in all groups. This latter change in VCSS was significantly prominent in B2 group with greater GSV diameter treated with less than $90 \mathrm{~J} / \mathrm{cm}$ with $P<0.02$. This finding suggests that increasing the energy level alongside with the GSV diameter is not necessary, particularly when the postoperative outcome in the early and the mid-term outcome. This finding was also significant for the A2 group, but barely reached significance $(P=0.05)$. In contrast, patients treated with higher energy levels had more complaints of leg pain and ankle swelling at 3 month controls.

\section{Conclusion}

In conclusion, EVLA is a valid option for VV treatment with acceptable early to midterm outcomes. Increasing energy levels may not affect the success of the procedure, yet probably cause more leg pain or ankle swelling.

\section{References}

[1] Carpentier, P.H., Maricq, H.R., Biro, C., et al. (2004) Prevalence, Risk Factors and Clinical Patterns of Chronic Venous Disorders of Lower Limbs: A Population-Based Study in France. Journal of Vascular Surgery, 40, 650-659. http://dx.doi.org/10.1016/j.jvs.2004.07.025

[2] Sisto, T., Reunanen, A., Laurikka, J., et al. (1995) Prevalence and Risk Factors of Varicose Veins in Lower Extremities: Mini-Finland Health Survey. European Journal of Surgical Oncology, 161, 405-414.

[3] Evans, C.J., Fowkes, F.G., Ruckley, C.V., et al. (1999) Prevalence of Varicose Veins and Chronic Venous Insufficiency in Men and Women in the General Population: Edinburgh Vein Study. Journal of Epidemiology and Community Health, 53, 149-153. http://dx.doi.org/10.1136/jech.53.3.149 
[4] Jawien, A., Grzela, T. and Ochwat, A. (2003) Prevalence of Chronic Venous Insufficiency in Men and Women in Poland: Multicentre Cross-Sectional Study in 40,095 Patients. Phlebology, 18, 110-122. http://dx.doi.org/10.1258/026835503322381315

[5] Nelzén, O., Bergqvist, D. and Lindhagen, A. (1994) Venous and Non-Venous Leg Ulcers: Clinical History and Appearance in a Population Study. British Journal of Surgery, 81, 182-187. http://dx.doi.org/10.1002/bjs.1800810206

[6] Wright, D.D., Franks, P.J., Blair, S.D., et al. (1991) Oxerutins in the Prevention of Recurrence in Chronic Venous Ulceration: Randomized Controlled Trial. British Journal of Surgery, 78, 1269-1270. http://dx.doi.org/10.1002/bjs.1800781039

[7] Ragnarson Tennvall, G. and Hjelmgren, J. (2005) Annual Costs of Treatment for Venous Leg Ulcers in Sweden and the United Kingdom. Wound Repair and Regeneration, 13, 13-18. http://dx.doi.org/10.1111/j.1067-1927.2005.130103.x

[8] Jantet, G. (1992) Impact socio-économique de la pathologie veineuse en Grande Bretagne. Phlébologie, 45, $433-437$.

[9] Subramonia, S. and Lees, T. (2005) Sensory Abnormalities and Bruising after Long Saphenous Vein Stripping: Impact on Short-Term Quality of Life. Journal of Vascular Surgery, 42, 510-514. http://dx.doi.org/10.1016/j.jvs.2005.05.021

[10] Wood, J.J., Chant, H., Laugharne, M., et al. (2005) A Prospective Study of Cutaneous Nerve Injury Following Long Saphenous Vein Surgery. European Journal of Vascular and Endovascular Surgery, 30, 654-658. http://dx.doi.org/10.1016/j.ejvs.2005.06.009

[11] Morrison, C. and Dalsing, M.C. (2003) Signs and Symptoms of Saphenous Nerve Injury after Greater Saphenous Vein Stripping: Prevalence, Severity, and Relevance for Modern Practice. Journal of Vascular Surgery, 38, 886-890. http://dx.doi.org/10.1016/S0741-5214(03)00790-0

[12] Davies, A.H., Steffen, C., Cosgrove, C. and Wilkins, D.C. (1995) Varicose Vein Surgery: Patient Satisfaction. Journal of the Royal College of Surgeons of Edinburgh, 40, 298-299.

[13] Mackay, D.C., Summerton, D.J. and Walker, A.J. (1995) The Early Morbidity of Varicose Vein Surgery. Journal of the Royal Naval Medical Service, 81, 42-46.

[14] Critchley, G., Handa, A., Maw, A., Harvey, A., Harvey, M.R. and Corbett, C.R. (1997) Complications of Varicose Vein Surgery. Annals of the Royal College of Surgeons of England, 79, 105-110.

[15] Miller, G.V., Lewis, W.G., Sainsbury, J.R. and Macdonald, R.C. (1996) Morbidity of Varicose Vein Surgery: Auditing the Benefit of Changing Clinical Practice. Annals of the Royal College of Surgeons of England, 78, 345-349.

[16] Kostas, T., Ioannou, C.V., Touloupakis, E., Daskalaki, E., Giannoukas, A.D., Tsetis, D., et al. (2004) Recurrent Varicose Veins after Surgery: A New Appraisal of a Common and Complex Problem in Vascular Surgery. European Journal of Vascular and Endovascular Surgery, 27, 275-282.

[17] van Rij, A.M., Jiang, P., Solomon, C., Christie, R.A. and Hill, G.B. (2003) Recurrence after Varicose Vein Surgery: A Prospective Long-Term Clinical Study with Duplex Ultrasound Scanning and Air Plethysmography. Journal of Vascular Surgery, 38, 935-943. http://dx.doi.org/10.1016/S0741-5214(03)00601-3

[18] Fischer, R., Linde, N., Duff, C., Jeanneret, C., Chandler, J.G. and Seeber, P. (2001) Late Recurrent Saphenofemoral Junction Reflux after Ligation and Stripping of the Greater Saphenous Vein. Journal of Vascular Surgery, 34, $236-240$. http://dx.doi.org/10.1067/mva.2001.115802

[19] Lohr, J. and Kulwicki, A. (2010) Radiofrequency Ablation: Evolution of a Treatment. Seminars in Vascular Surgery, 23, 90-100. http://dx.doi.org/10.1053/j.semvascsurg.2010.01.004

[20] Johonson, G. and Rutherford, R.B. (1995) Varicose Veins: Patient Selection and Treatment. In: Rutherford, R.B., Ed., Vascular Surgery, 4th Edition, W.B. Saunders, Philadelphia, 1825-1828.

[21] Neser, R.A. and Caffaro, R.A. (2011) Invagination Stripping with Ultrasound-Guided Perivenous Tumescence: An Original Method of Great Saphenous Vein Stripping. Dermatologic Surgery, 37, 349-352. http://dx.doi.org/10.1111/j.1524-4725.2011.01885.x

[22] Skykes, T.C., Brookes, P. and Hickey, N.C. (2000) A Prospective Randomized Trial of Tourniquet in Varicose Vein Surgery. Annals of the Royal College of Surgeons of England, 82, 280-282.

[23] Proebstle, T.M., Moehler, T. and Herdemann, S. (2006) Reduced Recanalization Rates of the Great Saphenous Vein after Endovenous Laser Treatment with Increased Energy Dosing: Definition of a Threshold for the Endovenous Fluence Equivalent. Journal of Vascular Surgery, 44, 834-839. http://dx.doi.org/10.1016/j.jvs.2006.05.052

[24] Nisar, A., Shabbir, J., Tubassam, M.A., Shah, A.R., Khawaia, N., Kavanagh, E.G., et al. (2006) Local Anaesthetic Flush Reduces Postoperative Pain and Haematoma Formation after Great Saphenous Vein Stripping-A Randomized Controlled Trial. European Journal of Vascular and Endovascular Surgery, 31, 325-331. http://dx.doi.org/10.1016/j.ejvs.2005.08.006

[25] Min, R.J., Khilnani, N. and Zimmet, S.E. (2003) Endovenous Laser Treatment of Saphenous Vein Reflux: Long-Term 
Results. Journal of Vascular and Interventional Radiology, 14, 991-996. http://dx.doi.org/10.1097/01.RVI.0000082864.05622.E4

[26] Sharif, M.A., Soong, C.V., Lau, L.L., Corvan, R., Lee, B. and Hannon, R.J. (2006) Endovenous Laser Treatment for Long Saphenous Vein Incompetence. British Journal of Surgery, 93, 831-835. http://dx.doi.org/10.1002/bjs.5351 
Scientific Research Publishing (SCIRP) is one of the largest Open Access journal publishers. It is currently publishing more than 200 open access, online, peer-reviewed journals covering a wide range of academic disciplines. SCIRP serves the worldwide academic communities and contributes to the progress and application of science with its publication.

Other selected journals from SCIRP are listed as below. Submit your manuscript to us via either submit@scirp.org or Online Submission Portal.
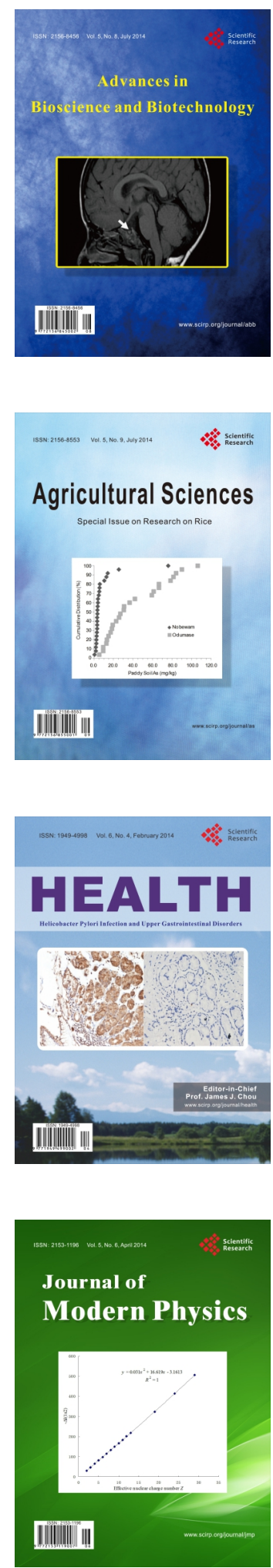
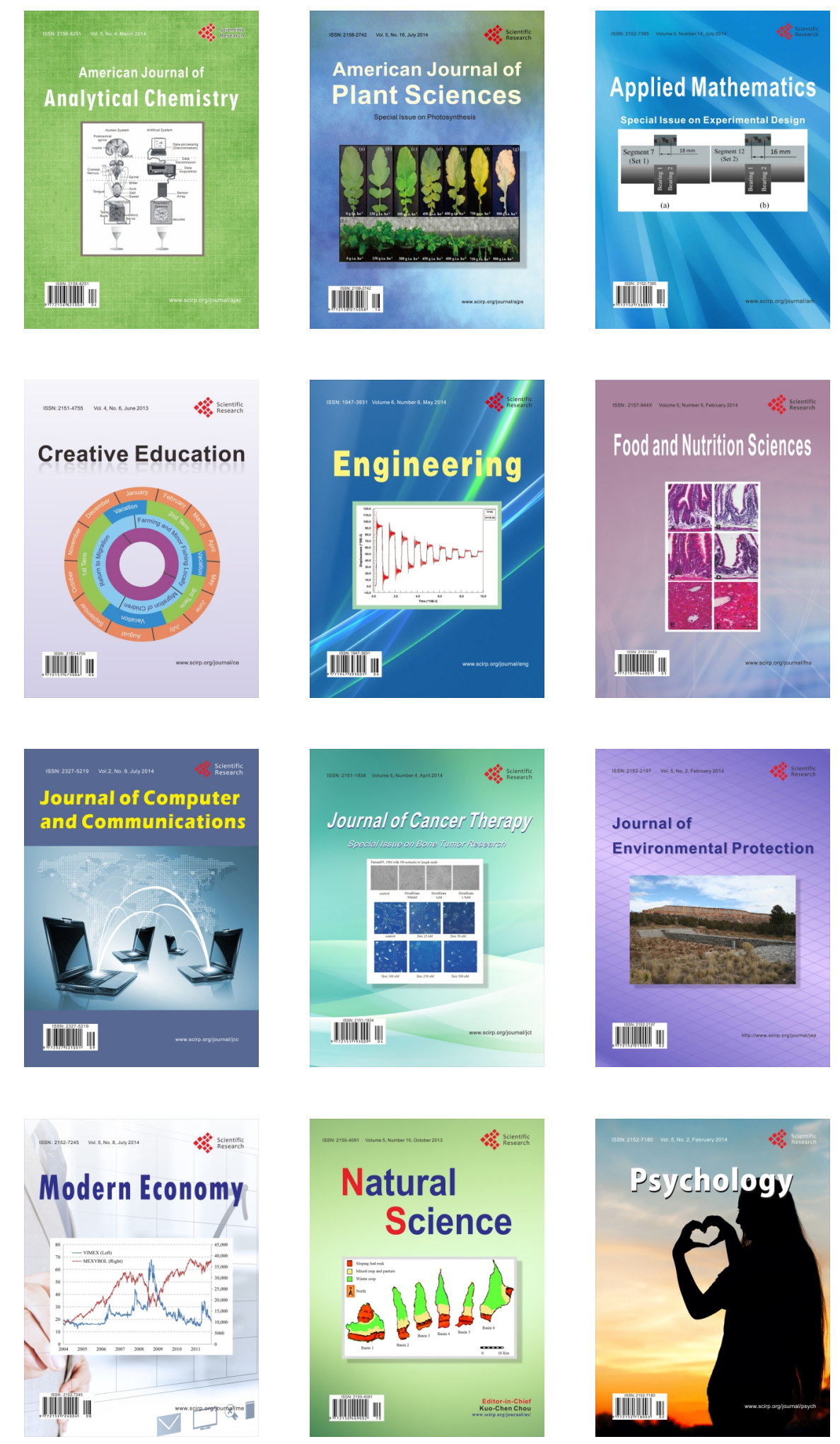